\title{
Igreja Católica e a Ditadura Militar em Belo Horizonte na década de 1960: uma Igreja e duas militâncias
}

\author{
Adriano Cecatto ${ }^{1}$
}

\begin{abstract}
RESUMO
A relação estabelecida entre Igreja e Estado no período da Ditadura Militar nos remete às transformações da própria Igreja e sua heterogeneidade de sujeitos e práticas, aproximações e distanciamentos do poder político. O objeto de estudo é a Igreja Católica de Belo Horizonte na década de 1960 e sua respectiva relação com o Estado, marcado pelo regime militar. Propomos analisar a relação entre Igreja e Estado, atentando para as tensões e conflitos entre essas instituições e internamente à própria Igreja e seus agentes. Na dimensão metodológica e documental, utilizaremos entrevistas. Podemos verificar que a Igreja de Belo Horizonte se caracterizou pela militância, tanto progressista como conservadora, que, em função dos conflitos internos dos grupos e práticas contraditórias, tardiamente posicionou-se contra o regime militar. Embora o clero se caracterizasse por assumir distintas opções políticas, principalmente em função das orientações de renovação eclesial proposta pelo Concílio Vaticano II, a hierarquia optou por uma postura de acomodação, tanto em relação ao Estado, quanto em relação aos seus agentes eclesiásticos.
\end{abstract}

Palavras-chave: Igreja Católica. Ditadura Militar. Política.

\begin{abstract}
The relationship established between the Church and State in the period of the Military Dictatorship makes us wonder about the transformations of the Church itself and its heterogeneity of subjects and practices, approximations and distanciations of the political power. The object of study is the Catholic Church of Belo Horizonte in the decade of 1960 and its respective relationship with the State, marked by the military regime. We propose to analyze the relationship between Church and State, considering the tensions and conflicts between these institutions and internally to the Church itself and its agents. In the methodological and documentary dimension, we will use interviews. We can verify that the Church of Belo Horizonte was characterized by militancy, both progressive and conservative, that due to the internal conflicts of groups and contradictory practices, belatedly opposed the military regime. Although the clergy was characterized by different political options, especially in view of the guidelines of ecclesial renewal proposed by the Second Vatican
\end{abstract}

\footnotetext{
${ }^{1}$ Doutorando em História pela Universidade Federal de Minas Gerais (UFMG). Atua principalmente nas seguintes temáticas: Catolicismo Brasileiro, Concílio Vaticano II, Ensino de História, Imagem, Formação Docente.
} 
Council, the hierarchy opted for a position of accommodation, both in relation to the State and in relation to its ecclesiastical agents.

Keywords: Catholic Church. Military dictatorship. Policy.

\section{Introdução}

Entre 1964 e 1968, o fechamento político e a recessão econômica desestimularam principalmente as classes médias, que, inicialmente, haviam apoiado o golpe militar no Brasil. Juntamente com a realidade de desrespeito aos direitos humanos com a repressão e prisões, parte da Igreja Católica deixou de apoiar o regime, "passando a constituir, nos anos seguintes, um dos principais focos de oposição, que, entretanto, sempre se abriu ao diálogo com os donos do poder" (RIDENTI, 2014, p. 35). A implantação do regime militar em 1964 foi um período em que se cultivaram distintas utopias, mas também de frustração de projetos (PASSOS, 2010). O catolicismo deste período foi ocupando outros espaços e práticas na sociedade, vivendo tensões e conflitos que possibilitaram a alteração de seu próprio perfil institucional (MATA, 1996; 2007). No entanto, há de se reconhecer que a Igreja Católica apoiou a intervenção militar por parte de sua hierarquia, principalmente por considerarem que João Goulart permitiria a implantação do comunismo no país (CANCIAN, 2016).

Segundo Motta (2014, p. 52), havia três fontes principais de ideologia: "nacionalismo autoritário, liberalismo e conservadorismo (e mais a tradição anticomunista, servindo como elo entre elas), cada uma com nuanças e peculiaridades que apontavam para políticas diferentes.” A despeito da dimensão conservadora, o catolicismo brasileiro reverberou e estabeleceu estratégias de combate ao comunismo por um longo período, antes e depois do golpe militar de 31 de março de 1964 (MOTTA, 2002).

Em Belo Horizonte, em 1956, surgiu o Movimento por um Mundo Cristão (MMC), que teve por intuito combater ideias modernistas, 
particularmente as ligadas ao marxismo. Além disso, os setores mais conservadores do catolicismo, tal como a Aliança Eleitoral pela Família (ALEF), interferiam nas eleições ao recomendarem que seus fiéis não votassem em candidatos do Partido Comunista (MOTTA, 2002). Os fatores que promoveram o golpe de 1964 foram de ordem política, de "reação à esquerdização", ao comunismo, combatido de forma veemente pela Igreja, pois "o golpe não foi essencialmente antirreformista, mas, principalmente, anticomunista (ou antiesquerdista)" (MOTTA, 2002, p. 39). A Igreja, por muito tempo, opositora ao comunismo, precisou lidar com o crescimento das esquerdas após 1960. Muitas lideranças, principalmente da Juventude Operária Católica (JOC), por exemplo, envolveram-se com políticas de esquerda, provocando o rompimento com o propósito inicial do movimento (MAINWARING, 1989).

A preocupação com a justiça social despertou novos horizontes para o catolicismo, que não se caracterizava por ser um bloco homogêneo, além de possuir práticas institucionais distintas e até mesmo por vezes contraditórias (CANCIAN, 2011; DELGADO e PASSOS, 2010; MAINWARING, 1989; MATA, 1996; PORTO, 2007). Como tratamos de um período em que o catolicismo adentrou os setores populares, faz-se necessário assinalar atores específicos, com iniciativas de grupos de leigos, sacerdotes e bispos, sujeitos esses que gradativamente envolveram-se com as questões políticas e sociais. ${ }^{2}$ Havia iniciativas de atores que contribuíram para as mudanças eclesiais, formando uma espécie de rede colaborativa que se propunha fomentar políticas institucionais ancoradas nas discussões do Concílio Vaticano II e na Conferência de Medellín (1968): Dom Helder Câmara (bispo de Olinda), Dom José de Medeiros Delgado (bispo de Fortaleza), Dom Antônio Batista Fragoso (bispo de Crateús), Dom Aluísio

\footnotetext{
2 Principalmente entre 1964 e 1973, a Igreja Católica do Brasil empreendeu esforço para estabelecer novas práticas pastorais junto dos setores populares. Destacou-se o envolvimento com os pobres, que ocorre mesmo antes dos agentes pastorais progressistas se envolverem com a política. Essa Igreja popular procurou inculturar a evangelização, rompendo com a prática excessivamente voltadas para sacramentos, ritos e cultos que ficavam no âmbito da exterioridade e não tocavam a real situação dos cristãos (MAINWARING, 1989).
} 
Lorscheider (bispo do Rio de Janeiro), Dom Paulo Evaristo Arns (bispo de São Paulo), Dom Jorge Marcos de Oliveira (bispo de Santo André), Dom José Maria Pires (bispo da Paraíba), Dom Pedro Casaldáliga (bispo de São Félix do Araguaia), entre outros, citando apenas os que compunham a hierarquia. ${ }^{3}$

Todavia, é preciso também sincronizar esse período da ditadura militar brasileira com a Igreja da América Latina, quando parte de seu episcopado manifestou as primeiras reações contra os regimes ditatoriais. Posturas contrárias a tais regimes foram articuladas institucionalmente pela Conferência Episcopal Latino Americana de Medellín (1968) e Puebla (1979), sustentadas nas discussões de renovação do Concílio Vaticano II (1962-1965), além da militância de inúmeros teólogos da libertação, muito, embora, tenhamos de levar em consideração que a elaboração dos respectivos documentos finais das Conferências Episcopais teve influência direta dos bispos progressistas. Gustavo Gutiérrez, expoente teólogo da libertação, problematizou e chamou a atenção sobre a realidade de miséria, exploração e repressão por que passavam os povos pobres do continente latino-americano. Em relação à ditadura, em sua obra publicada em 1971, Teologia da libertação: perspectivas, enfatizou a importância do posicionamento de sacerdotes engajados em trabalhos de áreas fronteiriças, junto da população rural e das periferias urbanas, quando assumiram postura de denúncia a toda forma de exploração econômica. Certos sacerdotes foram considerados subversivos, vigiados e procurados pela polícia; "outros acham-se na prisão, são expulsos do país (Brasil, Bolívia, Colômbia, República Dominicana, são exemplos significativos) ou assassinados por grupos terroristas anticomunistas" (GUTIÉRREZ, 1976, p. 95). Para Scott Mainwaring (1989 p. 103), após 1964, cada vez mais crescia o número de bispos progressistas, muito em função das "violações

\footnotetext{
3 O Concílio Vaticano II aconteceu entre 1962 e 1965, e teve como resultado a produção de constituições, decretos e declarações que orientaram a Igreja Católica nas dimensões dogmática e pastoral. "A eficácia histórica desse acontecimento estava em seus objetivos, nas suas orientações, nos documentos, enfim, na totalidade de seu dinamismo. Seu itinerário era provocar um aggiornamento, a atualização da Igreja. Buscar uma linha de unidade, diálogo, compreensão. Abrir-se para um verdadeiro diálogo com a modernidade (DELGADO; PASSOS, 2010, p. 111).
} 
generalizadas dos direitos humanos, a marginalização das classes populares, a repressão contra a Igreja e o fechamento de outros canais de dissidência." Ao passo que também criticou a omissão da Igreja a essa realidade, pelo fato de estabelecer relações de interesses econômicos com o Estado. Os bispos brasileiros tiveram certa cautela ao regime e, ao mesmo tempo, a esperança de que seria um movimento de curta duração; no entanto, "permaneceu praticamente em silêncio enquanto os católicos radicais eram presos e torturados" (SERBIN, 2001, p. 104). Nessa perspectiva, Delgado e Passos (2010, p. 121) evidenciam certo "afrouxamento" do apoio inicialmente concedido ao Estado, quando se verificou que "alguns membros da hierarquia eclesiástica se mantiveram numa fronteira indecisa ou menos divergente." Por sua vez, a prática do catolicismo entre as camadas populares, como tem descrito Mainwaring (1989) e Mata (1996), não pode necessariamente ser pensado em oposição ao regime militar brasileiro, embora muitas vezes tenha sido. O trabalho da Igreja junto aos pobres quase sempre foi interpretado, pelo regime, como prática subversiva ligada ao comunismo.

Desde o final do século XIX, a Igreja Católica estabeleceu uma leitura de mundo com posicionamento diante da realidade sócio-econômica, que pode ser verificado a partir da encíclica Rerum Novarum (1891), com o papa Leão XIII (MARCHI, 2001). Entretanto, foi após o Concílio Vaticano II que o catolicismo se propôs repensar suas práticas e estruturas, permitindo que as Igrejas locais de cada continente se adequassem às realidades culturais. Consoante Silveira (2014), nesse período, a Igreja do Brasil se viu institucionalmente impelida pelas diretrizes do Concílio Vaticano II a mudar seu lugar social, deslocando gradativamente para as periferias as suas atividades pastorais.

Para Alves (1979, p. 201), entre 1964 e 1967, as ideologias da Igreja e Estado "aproximavam-se através do anticomunismo, da recusa de qualquer experiência socialista e da pregação da harmonia entre as classes sociais como sendo uma meta desejável para a sociedade.” A intensificação dos 
conflitos entre essas instituições cresceu à medida que a Igreja ampliou o pensamento social e passou a se posicionar a favor dos pobres, sindicatos, Movimento de Educação de Base, movimentos da Ação Católica e, contrário ao sistema capitalista e o próprio regime militar; além do "envolvimento de padres e leigos na luta clandestina contra o Governo, envolvimento que consideravam como inextricavelmente ligado à sua fé" (ALVES, 1979, p. 202).

Nessa perspectiva, pretendemos analisar as tensões, aproximações e distanciamentos da Igreja Católica de Belo Horizonte em relação ao regime militar, assim como, as convergências e divergências que se refletiam no posicionamento dessa instituição. Como documento, utilizamos duas entrevistas que foram realizadas com Alberto Antoniazzi (AA) e Carlos Fragoso (CF). ${ }^{4}$ A História Oral pressupõe utilização de entrevistas e análise das mesmas com intuito de conhecer as experiências e cotidiano dos sujeitos (ALBERTI, 2008; LOZANO, 2006). Ao passo que pode ser instrumento para recuperar a memória e as experiências vividas, um método de pesquisa que possibilita "uma melhor compreensão da construção das estratégias de ação e das representações de grupos ou indivíduos" (FERREIRA, 2002, p. 330). A escolha dos entrevistados se deve à relevância que tiveram como sacerdotes, com práticas para além dos limites institucionais. Alberto Antoniazzi ${ }^{5}$ pode ser considerado de centro-esquerda, com atuações na academia, formação de seminaristas e contribuiu com o planejamento pastoral da Arquidiocese de Belo Horizonte, em conformidade com o que suscitou o Concílio Vaticano II. Por sua vez, Carlos Fragoso constituiu uma trajetória de militância junto ao operariado da Cidade Industrial, em Contagem-MG. As experiências

\footnotetext{
${ }^{4}$ Entrevistas realizadas em maio e março de 1995, pelo Núcleo de História Oral da Universidade Federal de Minas Gerais, sob responsabilidade de Sérgio Ricardo da Mata. O entrevistador defendeu a dissertação de mestrado no programa de pós-graduação em História da UFMG no ano de 1996. Cf. MATA, Sérgio Ricardo da. A fortaleza do catolicismo: identidades católicas e política na Belo Horizonte dos anos 60. 1996. 261f. Dissertação de Mestrado (Mestrado em História). Faculdade de Filosofia, Ciências e Letras da Universidade Federal de Minas Gerais, Belo Horizonte, 1996.

${ }^{5}$ Agrega-se a este sacerdote um número maior de informações, principalmente em função de sua trajetória formativa em termos de produção acadêmica e no trabalho com formação de novos padres, conforme Bonato (2009) e Caldeira, Bonato e Tosta (2013).
} 
políticas, eclesiológicas e acadêmicas estão atreladas às escolhas desses sujeitos, e consequentemente à leitura que fazem da realidade quando ambos integravam Conselho Presbiterial. ${ }^{6}$

\section{A Igreja de Belo Horizonte em militância}

O clero de Belo Horizonte encontrava-se dividido já nos anos de 1950, fato que transparecia no próprio Conselho Presbiterial. Dom Antonio dos Santos Cabral (1884- 1967) adoeceu em 1956 e não teria dado conta de aproximar e agregar o clero. Em 1957, Dom João Resende Costa assumiu a arquidiocese para tentar apaziguar os grupos que se "degladiavam". Acerca desses grupos, Mata $(1996 ; 2007)$ os caracteriza por identidade católica tradicionalista e identidade católica inclusiva. O primeiro era excludente, pouco permeável, as questões pastorais estavam pautadas numa liturgia e teologia tridentina; consideravam importante manter a harmonia nas relações entre Igreja e Estado, tendo como figura de liderança em Minas Gerais, Dom Geraldo Sigaud (1909-1999).7 Quanto ao segundo grupo, era minoritário e havia assimilado as propostas de mudanças/reformas do Concílio Vaticano II; portanto, não se caracterizavam como tradicionalistas e demonstravam abertura para as questões sociais, conforme descreveu Mata (1996, p. 149):

É composta de um grupo numeroso nos quadros da Ação Católica, em especial nos seus ramos estudantis e operários. Entre os sacerdotes, grosso modo é representada pelos assistentes eclesiásticos da $\mathrm{AC}$ e os responsáveis por paróquias situadas em bairros operários.

\footnotetext{
${ }^{6}$ É um organismo consultivo do bispo, formando um coletivo único, "onde se expressa na ação a comunhão do Presbitério da Igreja particular." Em certos casos, o consentimento jurídico depende da consulta a este conselho. Tal conselho não se limita à vida e ação dos sacerdotes, "mas é abrangente de toda a ação pastoral da diocese, conforme as afirmações explícitas do Concilio Vaticano II e do Código de Direito Canônico." (SCHLISINGER; PORTO, 1995, p. 688).

${ }^{7}$ Foi bispo de Diamantina-MG entre 1961 e 1980. "Junto a Antonio de Castro Mayer e Plínio Corrêa de Oliveira, é considerado um dos nomes do catolicismo conservador brasileiro no período préconciliar." (CALDEIRA, 2015, p.894). Na consulta prévia de João XXIII para a realização do Vaticano II, Dom Sigaud se posicionou contra a modernidade, o comunismo e a maçonaria. Coletou assinatura de bispos (450 assinaturas) a favor da condenação do comunismo, no decorrer do Vaticano II.
} 
No bairro Barro Preto, em Belo Horizonte, havia a casa Cura D'Ars, onde residiam alguns padres idosos de diferentes dioceses, que geralmente permaneciam após se aposentarem, e que também esteve Dom Geraldo Sigaud. Esses padres idosos tinham posicionamento político conservador, e entre outras estratégias, enviavam cartas anônimas, "cartas venenosas e satíricas sobre todas as novidades que apareciam" (ANTONIAZZI, 1995), como forma de garantir um modelo de Igreja (tridentina); assim como, estratégias de combate ao comunismo, que neste caso, se dava com a crítica à prática pastoral junto aos meios populares. ${ }^{8}$ Carlos Fragoso (1995) descreveu Dom Geraldo Sigaud como figura badalada pela imprensa, "era um líder de uma facção que pensava da maneira mais direitista possível". Importa considerar a influência de Dom Geraldo Sigaud sobre a Igreja mineira e internacional, que em 1964 teria pressionado a nunciatura a fim de que fosse transferido para a capital mineira com objetivo de afastar Dom João Resende Costa, "tido como demasiadamente fraco com o esquerdismo, o progressismo da Igreja Católica" (ANTONIAZZI, 1995). 9 Dom Geraldo Sigaud se posicionou contrário a reforma agrária e "apoiou ostensivamente, inclusive junto com o general Fragança, que era maçom, a revolução, o golpe militar" (ANTONIAZZI, 1995). Cabe destacar a rede de relações de forças estabelecida por Dom Geraldo Sigaud, que se articulava com outros bispos de Minas Gerais: Dom Geraldo Penido, de Juiz de Fora; Dom Oscar de Oliveira, de Mariana; Dom Alexandre Gonçalves, de Uberaba. Conforme Mainwaring (1989), entre 1963 e 1968, a Igreja Católica caracterizou-se pela reação antiesquerdista dinamizada pela efetivação da direita católica que garantiu presença na política brasileira.

A Igreja Católica de Belo Horizonte, no final da década de 1960 ainda se encontrava dividida. Existia um grupo de sacerdotes engajados com

\footnotetext{
${ }^{8}$ Acerca do posicionamento político conservador, Alves (1979, p. 226) definiu que "a participação da extrema-direita católica no debate ideológico que se trava no Brasil é considerável. A sua importância ultrapassa amplamente a zona de influência da Igreja. São os ideólogos católicos desta faç̧ão que fornecem aos militares no poder modelos e justificações. Defendem o corporativismo e o autoritarismo como instrumentos apropriados, se são únicos, para se alcançar o bem comum".

9 Sobre Dom Geraldo Sigaud, verificar a pesquisa de Caldeira (2011).
} 
políticas de esquerda, e os ditos conservadores ligados a uma espiritualidade e conceito de Igreja sem predisposição para mudanças. A década de 1960 para o catolicismo foi de política, com uma série de experiências junto às camadas populares, apoiando a participação dos leigos e alterando gradativamente a sua própria identidade (MAINWARING, 1989; MATA, 1996). Essas experiências contribuíram para repensar e renovar a própria prática católica. Os conflitos sociais adentravam e interferiam nos processos pastorais da Igreja de Belo Horizonte, suscitando uma clara divisão interna que se estabelecia nos debates dentro da instituição (BONATO, 2009; PASSOS, 2010). Segundo Sanchis (1992, p. 23), a Igreja Católica no Brasil precisava ser pensada não somente à partir de sua estrutura interna, porque "não é a Igreja que, por interesse, se volta para as classes populares, mas é a consciência de classe dos setores populares que a penetra e nela desencadeia uma mudança de lugar social."

Havia uma nova tomada de consciência da Igreja em relação às estruturas sociais da periferia, que se manifestavam no operariado de Contagem-MG. Carlos Fragoso relatou que somente 30\% dos padres da diocese estiveram envolvidos com essas questões sociais, pois era algo novo em termos de experiências e vivências eclesiais. Os sacerdotes envolvidos em trabalhos de cunho social eram apoiados por Dom João Resende Costa, que "apesar de não ter uma vivência tão profunda entre as camadas mais pobres, ele tinha uma grande sensibilidade pelo fato inclusive de ter que responder inquérito. Ele foi uma das pessoas indiciadas" (FRAGOSO, 1995). O envolvimento de Carlos Fragoso com a classe operária iniciou em 1961, entre os trabalhadores. Entre 1965 e 1969 cursou Ciências Sociais da Universidade Federal de Minas Gerais, o que denota que a escolha do curso esteve associada às experiências sociais junto do operariado.

No contexto do Concílio Vaticano II, Alberto Antoniazzi deixou Milão em 1963 e foi ordenado sacerdote em Belo Horizonte, em 1965; já possuía formação em filosofia, incluindo doutoramento na área. Uma memória marcada pela relação entre religião e política. Ingressou na Ação Católica de 
Milão em 1956, onde atuou como militante. Politicamente foi simpatizante de centro-esquerda. Pode ser considerado um intelectual engajado, mas acima de tudo, criador e mediador cultural à medida que produziu academicamente e estabeleceu relação desse saber com as comunidades eclesiais, além de dialogar com os diferentes grupos do catolicismo. Foi pesquisador (teólogo, sociólogo e historiador), além de professor e formador no Seminário Arquidiocesano Coração Eucarístico de Jesus e da Pontifícia Universidade Católica de Minas Gerais (CALDEIRA; BONATO; TOSTA, 2013).

Como militante, Alberto Antoniazzi caracterizou-se por exercer atividade intelectualizada acerca das questões pastorais e de fé, alertando a Igreja para os processos de mudanças, as quais precisava abrir-se para ampliar a ação pastoral das paróquias, assim como garantir presença entre as classes populares. Diante de uma Igreja dividida e conflituosa, que acabou influenciando o seminário, Alberto Antoniazzi foi nomeado para implementar os decretos do Concílio Vaticano II na formação dos sacerdotes. Todavia, trás à tona marcas de uma memória constituída em contato com sacerdotes conservadores e progressistas. Para Bonato (2009, p. 61), Alberto Antoniazzi estava imerso nesse contexto de polarização político-ideológico que marcou a sociedade brasileira e interferiu nas relações Igreja-Estado. Todavia, Dom João Resende Costa manteve postura política caracterizada pela acomodação, na medida em que evitava conflitos com o Estado e com os distintos posicionamentos do clero de sua arquidiocese, evitando confrontos diretos:

Bom, então, esse contexto parece indicar que Belo Horizonte era uma Igreja particularmente conflitiva e dividida no início dos anos 60. Essa pelo menos é a imagem que me foi dada. E eu não experimentei tão fortemente no seminário, porque o seminário era mais ou menos protegido. Dom João já estava fazendo uma política, vamos dizer, mais de pacificação, de bom senso, evitando dar corda aos extremismos etc. (ANTONIAZZI, 1995). 
Há dois importantes trabalhos sobre Alberto Antoniazzi (1937-2004), que nos ajuda conectar sua trajetória de vida ao recorte temporal, permitindo identificar elementos de proximidade e afastamento entre Igreja e Estado (BONATO, 2009; CALDEIRA, BONATO e TOSTA, 2013). Ambos justificam a escolha do objeto pelo fato de Antoniazzi ter percorrido determinada prática pastoral, engajamento político e ocupado espaços na academia; lecionou e publicou pesquisas nas áreas de Teologia e Filosofia. Sua experiência no catolicismo mineiro atrela-se aos aggiornamento proposto pelo Vaticano II (BONATO, 2009, p. 59). Diferentemente de Carlos Fragoso - não mais importante! -, Alberto Antoniazzi percorreu diversas frentes de trabalho, com distintos grupos e com importante produção acadêmica neste período.

Interessante observar que a Igreja Católica não tomou a iniciativa de ruptura com o Estado, mas foram os militares que o fizeram, obrigando-a a se definir:

Nunca a Igreja tomou realmente a iniciativa de romper. A não ser em alguns casos de algum ou outro padre, algum ou outro leigo, inclusive nem sempre, às vezes, os mais equilibrados [...] Mas no conjunto, a hierarquia nunca tomaria a iniciativa de ruptura (ANTONIAZZI, 1995).

Tal postura diz respeito à Dom João Resende Costa e sua respectiva linha política: "É preciso reconhecer que um sujeito tão passivo como o nosso arcebispo, que por formação e tudo, nunca pensou em brigar com o Estado brasileiro. E por ele, teria vivido em paz com o Estado, tranquilo, achando que isso no fundo era o ideal" (ANTONIAZZI, 1995). Se por um lado pode se reconhecer certa acomodação frente ao regime, em contrapartida, como elemento contraditório, possibilitou aos sacerdotes e leigos progressistas uma maior liberdade de ação junto às classes populares. Dentro dos quadros da Ação Católica, a Juventude Operária Católica e a Juventude Estudantil Católica tiveram apoio da hierarquia, ao passo que suas lideranças sofreram perseguição e violência política; esperavam um posicionamento da Igreja durante o regime militar (MATA, 2007). 
Analisando a leitura que Carlos Fragoso (1995) faz da atuação da Igreja, prescreve Dom João Resende Costa como uma figura anti-autoritária por permitir que sacerdotes progressistas e conservadores desenvolvessem seus respectivos trabalhos com autonomia, porém, "sempre restringia ou tentava restringir a participação daqueles que eram mais afoitos [...] identificados com a questão popular" (FRAGOSO, 1995). Dom João originouse na classe média paulista e teve dificuldade em compreender as questões relacionadas à pobreza. Por isso, tinha receio do envolvimento de alguns sacerdotes com o trabalho popular, até porque Dom João seria interrogado, caso houvesse denúncias.

Os bispos Dom João Resende Costa e Dom Serafim Fernandes de Araújo apoiavam a participação de leigos nos movimentos católicos, pois "a grande aposta de Dom Cabral a fim de buscar uma 'recristianização da sociedade' seria a Ação Católica” (MATA, 2007, p. 148). No entanto, a atuação dessa hierarquia ocorreu de forma ambígua na medida em que apoiou o golpe e, em seguida, facilitou a fuga de perseguidos políticos. A Conferência Nacional dos Bispos do Brasil (CNBB), temendo o comunismo (“desordem social"), inicialmente apoiou o regime e posteriormente opôs-se a ele. "Entre 1964 e 1968, a CNBB preocupou-se mais com sua ordem interna do que com a política e com a ação social" (MAINWARING, 1989, p. 104). A oposição ao regime militar não era homogênea, desde os moderados do MDB até os mais insatisfeitos com os rumos do regime, como foi o caso da Frente Ampla, liberais, setores eclesiásticos, e outros, que defendiam a restauração da democracia e um processo de "transição pacífica, através do diálogo e da persuasão" (REIS, 2014, p. 70).

Até o final de 1968, a Igreja não promovia práticas políticas radicais. A Igreja de Belo Horizonte era tida como conservadora, procurava passar uma imagem em sintonia com as mudanças propostas pelo Vaticano II, decidida a romper com o passado, quando na verdade o modelo de Igreja de Dom Cabral ainda se fazia presente. Conforme Azevedo (2004), essa instituição viveu mudança de paradigmas nos anos 1960, teria assumido 
uma postura conciliatória diante do Estado, mesmo que a CNBB tenha desempenhado "papel chave de articulação da sociedade civil, em defesa dos direitos humanos, das liberdades democráticas, da reforma agrária, dos direitos dos trabalhadores e da redemocratização" (AZEVEDO, 2004, p. 112). Todavia, há indícios de transformação com as práticas de uma Igreja popular articulada pontualmente por alguns sacerdotes, nas periferias. Essas práticas teriam sido consideradas pelo Estado como comunistas. Em 1968, o catolicismo de Belo Horizonte se preocupou em não perder o controle diante da crise interna, seja dos exageros pontuais de alguns sacerdotes ou mesmo da crise entre os padres e seminaristas.

Foi problemático pensar o aggiornamento proposto pelo Vaticano II na formação dos seminários do Brasil, entre 1960 e 1970, pois não teriam ocorrido os avanços modernizadores necessários (BONATO, 2009). Nesse período, a Igreja esteve em crise com a falta de vocações, seja em função das saídas ou das poucas entradas nos seminários. "Prevaleceu na Igreja do Brasil uma postura de enfrentamento dos problemas através da adoção de uma linha 'conservadora', calçada nas orientações de um modelo romano" (BONATO, 2009, p. 110). Tal postura teria impossibilitado a renovação da formação presbiterial e a constituição de um novo modelo de sacerdote sustentado na proposta eclesiológica sinalizada pelo Vaticano II.

Em novembro de 1968 foram presos três padres franceses, em Belo Horizonte. Tal incidente teria provocado desentendimento entre Igreja e Estado. A Igreja divulgou amplamente a tortura dos sacerdotes e, mesmo os membros declaradamente mais conservadores que até então não se posicionavam frente à ditadura, começaram a denunciar as ações arbitrárias do regime militar. Consoante Mainwaring (1989, p. 153),

a onda de repressão iniciou-se com a prisão e tortura de três padres e um diácono associado à JOC em Belo Horizonte, a 28 de novembro de 1968, duas semanas antes da decretação do $\mathrm{AI} n{ }^{\circ}{ }^{5}$. Os militares alegavam que os quatro, entre outras atividades subversivas, haviam instigado as greves em Contagem. 
Esse incidente teria contribuído para promover a conscientização da Igreja em relação às ações do regime, além de um possível sentido de coesão, "numa época em que a instituição ainda se encontrava profundamente dividida quanto à sua reação ao regime" (MAINWARING, 1989, p. 153). A harmonia entre as duas instituições terminou com as agitações de estudantes e greves operárias entre 1968 e 1969, com críticas ao autoritarismo do governo, protesto contra a violência e assassinato de estudantes. Os próprios seminaristas que estudavam no ICFT (Instituto Central de Teologia e Filosofia) suspenderam as aulas, e em assembleia, manifestaram o desejo por maior participação política. ${ }^{10}$ Ao mesmo tempo em que a hierarquia eclesiástica não se posicionava em relação ao Estado, também não interferia no clero, dando-lhe liberdade para o desenvolvimento de atividades pastorais e sociais. Segundo Mata (2007), no final de 1968 o clero estava mais dividido; havia os que cobravam de Dom João uma postura mais enérgica em relação à repressão militar e os que não almejavam ver a Igreja envolvida com a política. Por outro lado, é preciso considerar que "a estratégia militar era isolar os católicos radicais do resto da Igreja, de forma a evitar um conflito com a instituição inteira" (MAINWARING, 1989, p. 161). Interessante perceber que havia certo desconhecimento dos militares a respeito da Igreja Católica, quando num interrogatório ao padre Michel Le Ven, surgiu a pergunta: "Quem é o senhor Medellín, que o senhor está falando?" (ANTONIAZZI, 1995). Certamente o sacerdote mencionou a Conferência de Medellín (1968), que têm sido referência para o trabalho pastoral voltado para as classes populares, e que teve como núcleo de discussão a "Opção preferencial pelos pobres".

Em 28 de novembro de 1968, na greve de Contagem-MG foram presos sem provas os sacerdotes Michel Le Ven, Xavier Benthou, Hervé

\footnotetext{
${ }^{10}$ O ICFT foi fundado em 1967, junto da Universidade Católica de MG, por Dom João Resende Costa e Dom Serafim Fernandes de Araújo. Teve como intuito romper com o modelo de seminário tradicional (tridentino) e adequar-se ao "espírito do concílio". (MATA, 2007).
} 
Croguennec e o diácono José Geraldo da Cruz. ${ }^{11}$ Em relação a Michel Le Ven, era muito respeitado e conhecido, professor do ICFT e militante da JOC. "No máximo poderia dizer que o Michel estava nas aulas, liderando um tipo de reflexão mais radical, que poderia levar a contestar o governo, o Estado etc.” (ANTONIAZZI, 1995). Após a prisão, espancamento e tortura desses padres, o Conselho Presbiterial portou-se de modo homogêneo. Dom Serafim escreveu uma homilia que foi lida em todas as paróquias da diocese, denunciando a perseguição à Igreja, com clara postura de rompimento com a ditadura (MATA, 2007).

No dia 12 de dezembro, na comemoração do aniversário de Belo Horizonte, com a presença do presidente Costa e Silva, Dom João Resende Costa não compareceu ao cerimonial, em protesto às prisões. Alberto Antoniazzi mencionou ter levado a situação das prisões para o Vaticano, até por que possuía uma rede de relações com alguns bispos da Itália, que poderiam contribuir para que a Igreja se posicionasse contra a repressão. "Eu mesmo tinha que ir a Roma, fiz uns contatos, no caso o cardeal Rossi, em Roma, uma palavrinha até para o Paulo VI, e foi o representante de Estado que acompanhava o caso" (ANTONIAZZI, 1995). Segundo Alves (1979), "estabelece-se um conflito quando as partes em confronto se recusam a negociar as suas desavenças, quando os seus objetivos são contraditórios, quando as suas ideologias e os seus interesses são opostos." Compartilhando dessa ideia, Cancian (2011) nos remete pensar que a Igreja estabeleceu ações plurais, podendo coexistir internamente divisões ideológicas, entre os leigos, sacerdotes e bispos. Pelo que tudo indica, embora os objetivos institucionais e ideologias sejam de fato inconciliáveis, entre Estado e Igreja, esta última optou pela acomodação.

\footnotetext{
11 Em Belo Horizonte, ocorreram prisões em massa dos militantes da Ação Católica Operária e da Juventude Operária Católica. O convento dos dominicanos, tanto na capital quanto de Juiz de Fora, foi invadido, e entre os padres envolvidos, que eram referências nas atividades sindicais, políticas e sociais, pode-se mencionar: Francisco Lage, João Rodrigues de Freitas, José Jesus Gomes de Araújo, Jorge Solivellas Perelló, Mário Pinto, José Dumont, Cônego Francisco Maximiniano de Oliveira (CANCIAN, 2011).
} 
De fato, ocorreu uma espécie de divisão do clero, que se manifestava internamente no diz respeito às opções pastorais, e que era a principal preocupação de Dom João Resende Costa. "Ele entrou numa situação de grande divisão entre o clero - não só do clero, mas também do laicato, grupos de leigos com posições diferentes etc., religiosas, a respeito de apostolado e de pastoral" (FRAGOSO, 1995). Teria sido um bispo caracterizado pela conciliação, criticado pelos conservadores atrelados a Dom Geraldo Sigaud; "era um homem dividido no meio desse clero" (FRAGOSO, 1995), com uma hierarquia que não se posicionava por medo das conseqüências da repressão, exceto quando sacerdotes, religiosos e lideranças sofreram perseguições e violência.

Ao se referir às estratégias utilizadas entre a ditadura e os meios acadêmicos, Motta (2016) destaca que a acomodação fez parte da cultura política brasileira. ${ }^{12}$ Penso que pode ser aplicado nas relações entre Estado e Igreja, para compreender os posicionamentos/estratégias utilizados para a redução dos conflitos entre ambos. A opção do autor por acomodação no lugar de conciliação "permite integrar esse sentido e incluir também arranjos realizados em outros espaços sociais e institucionais com envolvimento de outros atores, como acadêmicos, cientistas, intelectuais e produtores culturais" (MOTTA, 2016, p. 16).

Estratégias de acomodação/negociação podem ser verificadas com o golpe de 1964 e esteve presente em momentos de crise política do país em diversos momentos de sua história (MOTTA, 2014). Essa acomodação pode ser visualizada nos encaminhamentos políticos da hierarquia eclesiástica, na figura de Dom João Resende Costa, tido como discreto e com postura equilibrada. Entretanto, embora não tenha deixado de se pronunciar contra as prisões e arbitrariedades do governo militar, permitiu que as situações se

\footnotetext{
12 "Seria um conjunto de representações, valores e padrões de comportamento político comuns a determinado grupo, sem que isso signifique qualquer forma de atavismo [...] Embora a cultura política implique relações sociais, valores culturais e imaginários estruturados, portanto, bem enraizados na sociedade, isso não significa que mudanças sejam impossíveis" (MOTTA, 2016, p. 14).
} 
estendessem e se resolvessem com o passar do tempo. "Nesse sentido, ele nunca foi precipitado, às vezes talvez deixou uma situação demorar muito. Outro teria intervido. Mas ele tinha uma certa tendência a intervir menos, a ter mais paciência" (ANTONIAZZI, 1995). O posicionamento de Dom João sinaliza para uma "Igreja do silêncio" (MATA, 2007), que refletia na reduzida participação do Conselho Presbiterial no tocante aos pronunciamentos públicos contra a ditadura.

É bastante provável que Dom João e Dom Serafim vissem com bons olhos esse recuo. Mesmo eles pareciam desconfiar da existência de marxistas e subversivos no clero. Tinham incentivado decisivamente o aggiornamento, mas não estavam dispostos a arcar com todas as suas conseqüências- sobretudo as políticas (MATA, 2007, p. 156).

Ao mesmo tempo que Antoniazzi (1995) estabeleceu críticas à Dom João Resende Costa, também o defendeu por ser conciliador e ponderar os diferentes interesses, quando ressalta a postura da Igreja diante da prisão dos sacerdotes. Nesse caso, a conciliação teria sido efetiva junto do Conselho Presbiterial:

tomaram uma posição firme, não se tratava inclusive nem de defender os padres franceses, o que estava em jogo era a Igreja de Belo Horizonte. Já atacada com insinuações etc. Se queria mostrar que não era uma Igreja com infiltração comunista, que era uma Igreja que estava dentro do seu direito e que não tinha medo de falar (ANTONIAZZI, 1995).

Nessa relação com a política, a hierarquia eclesiástica de Belo Horizonte procurou estabelecer uma imagem de unidade e coerência, mesmo diante da diversidade que a compunha, que segundo Mainwaring (1989, p.16), "a tendência em proteger interesses organizacionais tem sido e continuará sendo, dessa forma, um elemento chave no envolvimento da Igreja Católica na política.” Neste caso, adesão e acomodação ocorreu em relação ao regime militar, mas também internamente à Igreja, quando a hierarquia se posicionou contrária às ações do Estado; ao passo que silenciou diante da necessidade de evidenciar tomadas de posições mais radicais em 
relação às arbitrariedades e ataques aos direitos humanos. Nesse sentido, Ridenti (2014) assinala ser necessário compreender a relação entre "dominantes e dominados" à partir das negociações e concessões que contribuíram para dar legitimidade ao regime militar, tendo em vista que "as oposições à ditadura na sociedade brasileira devem ser compreendidas de modo relacional, envolvendo zonas intermediárias entre colaborar e resistir" (RIDENTI, 2014, p. 30).

As ações repressivas contribuíram para agravar os conflitos entre os católicos conservadores e progressistas, que embora com posicionamentos políticos e pastorais contrários, institucionalmente começaram a denunciar a violência sobre seus agentes e as demais vítimas do regime. Isso se deve, em grande medida, a alguns bispos que assumiram postura de denúncia às torturas e às políticas econômicas - até por que a Igreja não pode ser entendida por um bloco homogêneo. "As condenações proféticas dos bispos foram um divisor de águas. Não constituíram apenas inovações teológicas, mas declarações com a intenção de atacar o regime politicamente" (SERBIM, 2001, p. 107). Uma das formas de resistência da Igreja de Belo Horizonte à repressão foi esconder revolucionários que estavam sendo perseguidos pelas forças armadas. Um grupo de sacerdotes utilizou-se de um centro social para enviar e receber correspondências, a fim de evitar a interceptação das informações. Da mesma forma, os confessionários serviam de espaços para socializar mensagens acerca de prisioneiros políticos. E nesse contexto emblemático, setores progressistas se fortaleceram na medida em que houve relativa unidade e coesão na hierarquia, em prol de uma integridade institucional.

Interessante observar que em 1969 o Conselho Presbiterial viveu certa tensão em relação ao regime militar. A despeito desse problema, a divisão interna do clero se apresentava no âmbito deste Conselho, que segundo Alberto Antoniazzi (1995), sempre manteve uma linha de centro, com postura pouco eficaz diante do Estado, mas garantindo proteção aos movimentos da Ação Católica, apoiando inclusive a candidatura do operário 
"Dadazinho", de Nova Lima-MG. No entanto, Alberto Antoniazzi mostra-se contraditório ao mencionar que o Conselho seria de extrema direita, pelo fato de Dom João e Dom Serafim optarem por uma política de "pacificação do clero", evitando os extremismos. Ao que tudo indica o Conselho Presbiterial não era composto somente por "extrema direita" e "esquerda", mas também de centro e com tendência de centro-esquerda. Isso se deve às crescentes iniciativas de sacerdotes e militantes envolvidos com atividades sindicais e pastorais nas periferias da capital (MATA, 1996).

Todavia, Alberto Antoniazzi nos remete à ideia de que o próprio povo católico estava dividido, referindo-se aos leigos. Havia uma imagem de esquerda dentro do catolicismo que não existia: "Figuras que tendem a pintar uma imagem infernal da Igreja de Belo Horizonte, quando na realidade estávamos muito longe de ter o esquerdismo, a revolução etc." (ANTONIAZZI, 1995). Isso pode ser verificado em figuras como o Padre Viegas, que tinha simpatias políticas de esquerda, não encontrou espaço na capital mineira, acabou mudando-se para São Paulo e posteriormente deixando o sacerdócio. No entanto, é preciso considerar a heterogeneidade de práticas desse catolicismo, reconhecendo a alteração do seu lugar social, com o desenvolvimento de trabalhos junto das periferias e da classe trabalhadora. A hierarquia católica que sempre se apresentou complacente frente aos poderes públicos, pouco preocupada com as mudanças nas estruturas sociais, começou a destinar maior atenção. E isso se deve, em grande medida à organização interna que a própria Igreja vivenciava a partir das orientações do Vaticano II e da Conferência de Medellín (1968).

De fato, a relação com o Estado rompeu-se no final da década de 1960, quando a Igreja assumiu, por meio da CNBB e a hierarquia, a opção por defender os direitos humanos e a justiça social. Após a publicação do AI-5, com as constantes prisões e torturas e a repressão contra a própria hierarquia e seus lideres de movimentos leigos e sindicais, que tal rompimento ocorreu de forma gradativa nas diferentes realidades dessa instituição. 
Nessa relação entre Igreja e política, a questão central é perceber como ocorre tal envolvimento. O engajamento eclesiástico no ativismo político teria suas motivações nas diretrizes pastorais do Concílio Vaticano II, estimulando a participação crescente da Igreja católica na sociedade, num momento de alterações da identidade do próprio catolicismo, que diz respeito ao alargamento de suas práticas. Por sua vez, embora setores do catolicismo tenham se comprometido com as questões políticas e sociais, com a defesa dos direitos humanos, o fizeram nos "limites da institucionalidade", aproveitando-se da liberdade concedida pelo Estado e pela hierarquia eclesiástica que já não conseguiam mediar os conflitos. A prática progressista da Igreja, tão perseguida pelo regime militar, em grande medida já se realizava em função das próprias mudanças pelas quais a instituição vinha passando em nível internacional.

A memória dos entrevistados aponta para ambiguidades e conflitos. A Igreja de Belo Horizonte estava de fato dividida e fazia esforço de adequação de suas práticas ao aggionamento proposto pelo Vaticano II. O bispo Dom João Resende Costa foi figura central, marcadamente com postura de acomodação, tanto em relação ao clero, quanto ao regime militar. Embora esse bispo declinasse sobre práticas conservadoras, se mostrou flexível com os grupos progressistas, tendo apoiado os movimentos de Ação Católica. Nesse sentido, o Conselho Presbiterial, heterogêneo em sua composição, não era simpatizante ao regime militar e cobrava posicionamento de Dom João e Dom Serafim.

Entre as décadas de 1960 e 1970, a Igreja Católica do Brasil se apresentou como uma das únicas instâncias de peso possíveis que se posicionou contra o regime autoritário. Considerando as características de seus líderes, a Igreja de Belo Horizonte e as tensões vivenciadas internamente diante da heterogeneidade de posturas políticas, só tardiamente emitiu um posicionamento concreto nessa direção. Todavia, não se pode desconsiderar as opções políticas de alguns atores sociais, sacerdotes e leigos militantes, que se comprometeram com as classes populares em suas 
práticas pastorais por meio de lutas sindicais e movimentos leigos de esquerda. A prática desses atores sofreu repressão e representou postura de resistência ao Estado, mesmo estando vinculados a uma hierarquia conservadora que evitava relações de conflito.

A Igreja se opôs muito timidamente ao regime militar e, foi mais enérgica quando ocorreram as prisões dos sacerdotes. No entanto, tal posicionamento teria sido pouco efetivo, considerando as características de Dom João Resende Costa, que optava por postura de pacificação e acomodação como estratégia política. Por sua vez, neste caso pode-se dizer que não foi a Igreja que rompeu relações com o regime militar, mas o próprio Estado que se impôs sobre a "Igreja do silêncio". Nesse sentido, a "pacificação" e "flexibilidade" da hierarquia permitiram a postura de acomodação, suavizando a repressão e os conflitos entre Igreja e Estado, e entre o próprio clero.

\section{Referências bibliográficas}

ALVES, Marcio Moreira. A Igreja e a política no Brasil. São Paulo: Editora Brasiliense, 1979.

AZEVEDO, Dermi. A Igreja católica e seu papel político no Brasil. Estudos Avançados, São Paulo, v.18, n.52, p.109-119, 2004.

ALBERTI, Verena. Fontes orais: histórias dentro da história. In: PINSKY, Carla B. (Org.). Fontes históricas. 2. ed. São Paulo: Contexto, 2008, p.155-202.

BONATO, Massimo. Transformações do catolicismo brasileiro pós-Concílio Vaticano II: uma análise da ação pastoral do padre Alberto Antoniazzi. 2009. 130 f. Dissertação de Mestrado (Mestrado em História) - Instituto de Filosofia e Ciências Sociais da Universidade Federal do Rio de Janeiro, Rio de Janeiro, 2009.

CALDEIRA, Rodrigo Coppe; BONATO, Massimo; TOSTA, Sandra. Alberto Antoniazzi: intelectual católico comprometido com o aggiornamento da Igreja do 
Brasil. In: RODRIGUES, Cândido Moreira.; ZANOTTO, Gizele (ORGs.) Catolicismos e sociabilidade intelectual no Brasil e na Argentina. Cuiabá: EDUFMT, 2013, p.275-304.

CALDEIRA, Rodrigo Coppe. Os baluartes da tradição: o conservadorismo católico brasileiro no Concílio Vaticano II. Curitiba, PR: Editora CRV, 2011.

Geraldo de Proença Sigaud. In: PASSOS, João Décio; SANCHEZ, Wagner Lopes (Orgs.). Dicionário do Concílio Vaticano II. São Paulo: Paulus, 2015, p.894895.

CANCIAN, Renato. Igreja Católica e ditadura militar no Brasil. São Paulo: Claridade, 2011.

- Conflito Igreja-Estado no período da ditadura militar revisitando aspectos teóricos das abordagens institucionais. Revista Angelus Novus, São Paulo, Ano VII, n. 11 , p. $95-116,2016$.

DELGADO, Lucilia de Almeida Neves; PASSOS, Mauro. Catolicismo: direitos sociais e direitos humanos (1960-1970). In: FERREIRA, Jorge; DELGADO, Lucilia de Almeida Neves (Orgs.). O Brasil republicano: o tempo da ditadura: regime militar e movimentos sociais em fins do século XX. 4. ed. Rio de Janeiro: Civilização Brasileira, 2010, p.93-131.

FERREIRA, Marieta de Moraes. História, tempo presente e história oral. Topoi, Rio de Janeiro, v.3, n.5, p.314-332, dez., 2002. Disponível em: http://www.revistatopoi.org/numeros anteriores/topoi05/topoi5a13.pdf Acesso em: 15/09/2014.

GUTIÉRREZ, Gustavo. Teologia da Libertação: perspectivas. 2. ed. Petrópolis, RJ: Vozes, 1976.

LOZANO, Jorge E. A.. Prática e estilos de pesquisa na história oral contemporânea. In: FERREIRA, Marieta de Moraes.; AMADO, Janaina. Usos e abusos da história oral (Orgs.). 8. ed. Rio de Janeiro: Fundação Getúlio Vargas, 2006, p.15-25. 
MARCHI, Euclides. A Igreja do Brasil e o plano de emergência - 1952/1962. Revista de Ciências Humanas, Florianópolis: EDUFSC, n.30, p.81-108, out., 2001.

MATA, Sérgio da. A fortaleza do catolicismo: identidades católicas e política na Belo Horizonte dos anos 60. 1996. 261f. Dissertação de Mestrado (Mestrado em História). Faculdade de Filosofia, Ciências e Letras da Universidade Federal de Minas Gerais, Belo Horizonte, 1996.

A dialética do aggiornamento. Revista do Arquivo Público Mineiro, Belo Horizonte, v. 43, p. 144-157, 2007. Disponível em: http://www.siaapm.cultura.mg.gov.br/acervo/rapm_pdf/A_dialetica_do\%20_aggiorn amento.PDF>. Acesso em: 14 de junho. 2017.

MAINWARING, Scott. A Igreja Católica e a política no Brasil (1916-1985). São Paulo: Brasiliense, 1989.

MOTTA, Rodrigo Patto. Em guarda contra o perigo vermelho: o anticomunismo no Brasil (1917-1964). São Paulo: Perspectiva; FAPESPE, 2002.

A modernização autoritário-conservadora nas universidades e a influência da cultura política. In: REIS, Daniel Aarão; RIDENTI, Marcelo; MOTTA, Rodrigo Patto Sá (Orgs.). A ditadura que mudou o Brasil: 50 anos do golpe de 1964. Rio de Janeiro: Zahar, 2014, p.48-65.

. A estratégia de acomodação na ditadura militar brasileira e a influência da cultura política. Revista Digital de la Escuela de Historia, Rosario-Argentina, ano 8, v. 8, n.17, p.9-25, 2016 .

PASSOS, Mauro. Um catolicismo a caminho - cruzamentos e travessias do catolicismo em Belo Horizonte na década de 1970. In: PASSOS, Mauro (Org.). Diálogos cruzados: religião, história e construção social. Belo Horizonte, MG: Argvmentvm, 2010, p.185-210.

PORTO, Márcio de Souza. Dom Delgado na Igreja de seu tempo (1963-1969). 2007. 215 f. Dissertação (Mestrado em História) - Centro de Humanidades, Universidade Federal do Ceará, Fortaleza, 2007. 
REIS, Daniel Aarão. Ditadura e democracia no Brasil: do golpe de 1964 à Constituição de 1988. Rio de Janeiro: Zahar, 2014.

RIDENTI, Marcelo. As oposições à ditadura: resistência e integração. In: REIS, Daniel Aarão; RIDENTI, Marcelo; MOTTA, Rodrigo Patto Sá (Orgs.). A ditadura que mudou o Brasil: 50 anos do golpe de 1964. Rio de Janeiro: Zahar, 2014, p.30-47.

SANCHIS, Pierre. Introdução. In: SANCHIS, Pierre (Org.). Catolicismo: modernidade e tradição. São Paulo: Edições Loyola, 1992, p.9-39.

SERBIN, Kenneth. Diálogos na sombra: bispos e militares, tortura e justiça social na ditadura. São Paulo: Companhia das Letras, 2001.

SCHLISINGER, Hugo; PORTO, Humberto. Dicionário enciclopédico das religiões. Petrópolis, RJ: Vozes, 1995, p.688.

SILVEIRA, Diego Omar. Das catacumbas: os homens da Igreja e a renovação do catolicismo durante a ditadura civil-militar no Brasil. In: Daniel Aarão Reis Filho; Diego Omar da Silveira; Isabel Cristina Leite; Janaína Martins Cordeiro. (Orgs.). À sombra das Ditaduras. Brasil e América Latina. Rio de Janeiro: Mauad X, 2014, v., p. $39-50$.

\section{Documentos}

ANTONIAZZI, Alberto. Entrevista [26 de maio de 1995]. Entrevistador: Sérgio Ricardo da Mata. Entrevista na íntegra transcrita e disponível no Núcleo de História Oral da UFMG.

FRAGOSO, Carlos. Entrevista [21 de março de 1995]. Entrevistador: Sérgio Ricardo da Mata. Entrevista na íntegra transcrita e disponível no Núcleo de História Oral da UFMG. 